\title{
18-49 Yaş Grubu Evli Kadınların Anne Sütü Bankalarına İlişkin Bilgi ve Görüşlerinin Belirlenmesi
}

\section{Determination of Knowledge and Views of Married Women Aged 18-49 About Breast Milk Banks}

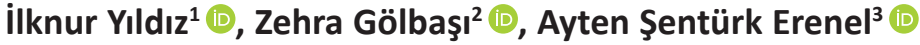

\begin{abstract}
${ }^{1}$ Sivas Cumhuriyet Üniversitesi, Sağıık Bilimleri Fakültesi, Hemşirelik Bölümü Çocuk Sağlığı ve Hastalıkları Hemşireliği Anabilim Dalı, Sivas, Türkiye ${ }^{2}$ Lokman Hekim Üniversitesi, Sağlık Bilimleri Fakültesi, Hemşirelik Bölümü, Doğum ve Kadın Hastalıkları Hemşireliği Anabilim Dalı, Ankara, Türkiye ${ }^{3}$ Gazi Üniversitesi, Sağlık Bilimleri Fakültesi, Hemşirelik Bölümü, Doğum ve Kadın Hastalıkları Hemşireliği Anabilim Dalı, Ankara, Türkiye
\end{abstract}

ORCID ID: I.Y. 0000-0002-2574-7018; Z.G. 0000-0002-0410-7433; A.Ş.E. 0000-0002-0841-2099

Atıf/Citation: Yildiz I, Golbasi Z, Senturk Erenel A. 18-49 yaş grubu evli kadınların anne sütü bankalarına ilişkin bilgi ve görüşlerinin belirlenmesi. Çocuk Dergisi - Journal of Child 2021;21(2):183-190. https://doi.org/10.26650/jchild.2021.2.823030

Öz

Amaç: Bu çalışma 18-49 yaş grubu evli kadınların anne sütü bankalarına ilişkin bilgi ve görüşlerini belirlemek amacıyla tanımlayıcı olarak yapılmıştır.

Gereç ve Yöntem: Araştırma Sivas il merkezinde yer alan iki Aile Sağlığı Merkezi (ASM)'nde yürütülmüştür. Belirtilen ASM'lere 31.10.201831.12.2018 tarihleri arasında çeşitli nedenlerle başvuran ve araştırmaya katılmayı kabul eden 18-49 yaş grubundaki evli kadınlar ( $n=190)$ araştırmanın örneklemini oluşturmuştur. Veriler araştırmacılar tarafından geliştirilen bir form kullanılarak toplanmıştır. Veriler SPSS 22 programında sayı, yüzde, ortalama ve standart sapma değerleri ile sunulmuş, istatistiksel analizde ki-kare testi kullanılmıştır.

Bulgular: Kadınların \%67,4'ü anne sütü bankasını duymamış, \%90,5'i Türkiye'de anne sütü bankası olup olmadığını bilmemekte, $\% 32,6$ 'sı anne sütü bankası kurulmasını istememektedir. Buna karşın kadınların \%35,3'ü ihtiyacı olduğunda bebeğini beslemek için süt bankasından süt alabileceğini, \%46,8'i sütünü bankaya bağışlayabileceğini, \%61,1'i anne sütü bankasından alınan sütlerin bebekler için mamadan daha iyi bir seçenek olacağını belirtmiştir.

Sonuç: Kadınların anne sütü bankalarına yönelik tutumları nispeten olumludur. Türkiye'de anne sütü bankalarına ilişkin bilgilendirilme çalışmalarının yaygınlaştırılması ve mevcut kaygılara ilişkin sektörler arası bilgilendirme ve işbirliği yapılması önerilmektedir.

Anahtar Kelimeler: Süt bankaları, bilgi, tutum
ABSTRACT

Objective: This study was performed descriptively to determine th eknowledge and views of married women aged 18-49 regarding breast milk banks.

Materials and Methods: The study was carried out at two Family Health Centers (FHC) in Sivas city center. The married women $(n=190)$ aged between 18 and 49 who applied to the specified FHC between $31^{\text {st }}$ October and $31^{\text {st }}$ December, 2018, for various reasons and who agreed to be included in the study constituted the sample of the study. The data were collected by the researchers by means of a questionnaireand then presented in SPSS 22 program with number, percentage, mean and standard deviation values. The chi-square test was used for statistical analysis.

Results: It was found that $67.4 \%$ of women had never heard about breast milk banks, $90.5 \%$ did not know of the existence of breast milk banks in Turkey, and $32.6 \%$ were unwilling for breast milk banks to be established. The study further concluded that $35.3 \%$ of the womencould benefit from breast milk banks when needed. Moreover, $46.8 \%$ of the women said that they would donate their breast milkand $61.1 \%$ stated that breast milk from a bank is a better option for infants than formula milk.

Conclusions: Women's attitudes towards breast milk banks are relatively positive. A recommendation arising from this study is that information about breast milk banks in Turkey should be more readily available and that there should be morecollaboration between sectors on current concerns.

Keywords: Milkbanks, knowledge, attitude

Sorumlu Yazar/Corresponding Author: illknur Yıldız E-mail: ilknuryildiz@yahoo.com.tr

Başvuru/Submitted: 08.11.2020 • Revizyon Talebi/Revision Requested: 26.11.2020 • Son Revizyon/Last Revision Received: 07.05.2021 • Kabul/Accepted: 07.05.2021 


\section{EXTENDED ABSTRACT}

Introduction and Objective: Breast milk is the best source of nutrition as it meets all the requirements of a baby. It is considered that breast milk banks are the most suitable option when a baby cannot receive the mother's milk for various reasons. This study was conducted to determine the knowledge and opinions of married women between the ages of 18and 49 on breast milk banks.

Materials and Methods: The study was conducted at two Family Healthcare Centers (FHCs) in the city center of Sivas. Married women $(n=190)$ in the $18-49$ age group admitted to the above-mentioned FHCs between October $31^{\text {st }}$ and December $31^{\text {st }}, 2018$, for various reasons, and who agreed to participate in the study, constituted the sampling of the study. Permissions to conduct the study were obtained from the Ethics Committee and from the institution. The purpose of the study was explained to the women, and their verbal and written consent was obtained. The data of the study were collected using a form that was developed by the researchers. There are a total of 31 questions on the form to determine the sociodemographic characteristics of the women and their knowledge and opinions of breast milk banks. The data obtained from the study were presented to the SPSS 22 program as numbers, percentages, mean, and standard deviation values, and the Chi-Square Test was used in statistical analyses.

Results: The mean age of the women who participated in the study was $32.08 \pm 7.52$ ( $\min : 19$, max:49), 28.9\% were primary school graduates, $57.9 \%$ were married for 10 years or under, and $93.2 \%$ were unemployed. It was found that $82.6 \%$ of the family types were nuclear families, $75.8 \%$ lived in the city center, and $81.6 \%$ had income equal to their expenses. The mean number of pregnancies, births, and living children were $2.56 \pm 1.55$, $2.15 \pm 1.36$, and $2.11 \pm 1.31$, respectively. A total of $86.3 \%$ of the women breastfed their babies, $20.1 \%$ terminated breastfeeding before the first six months, $42.7 \%$ started supplementary foods, and $21.3 \%$ said that they wanted to benefit from the breast milk bank during the breastfeeding process. Moreover, $75.8 \%$ of women had learned about breast milk banks from the media, $67.4 \%$ had not heard about breast milk banks at all, $90.5 \%$ did not know whether there was a breast milk bank in Turkey, and $32.6 \%$ did not want a breast milk bank to be established. It was found that $61.3 \%$ of the reasons for not wanting to have a milk bank established in Turkey were to do with religion, while $50 \%$ of the reasons stemmed from not knowing the milk donor, $29 \%$ from mixing the milk collected, and $21 \%$ from distrust in the registration system. However, $35.3 \%$ of the women said that they could buy milk from the milk bank to feed their baby when required, $46.8 \%$ said that they would donate their milk to the bank, and $61.1 \%$ said that the milk purchased from the breast milk bank would be a better option for babies than babymilk formula. Furthermore, $66.3 \%$ thought that they would support the establishment of breast milk banks in our country, $48.4 \%$ thought that breast milk banks were needed, 50.5\% thought that there would be a demand for breast milk banks, and $48.9 \%$ thought that breast milk banks were suitable for our society. While $32.1 \%$ of women said that purchasing milk from a milk bank would cause a social problemand $12.1 \%$ said that donating milk to a breast milk bank would be a sin, $61.1 \%$ said that milk from a breast milk bank was a better option for babies than the baby formula. However, $18.4 \%$ said that it would be dangerous for the health of the baby. Significant differences were detected between women's ages, education levels, places of residence, breastfeeding experiences, and knowledge about breast milk banks $(p<0.05)$.

Conclusion: It was found that women did not know enough about breast milk banks, and that while many want breast milk banks to be established, they have concerns about the religious, social, and health effects of such banks. Overall, women's attitudes towards these banks were found to be relatively positive. The study recommends that information on breast milk banks in Turkey be more widely circulated and that greater cooperation among sectors about the present concerns be established.

\section{Gíiş̧}

Anne sütü bebekler için ilk alt ayda en iyi besin kaynağı olmasının yanı sıra, özellikle yenidoğan yoğun bakım ünitelerinde bulunan bebekler için yaşamsal önemi bulunmaktadır $(1,2)$. Ancak anneye veya bebeğe ait bazı sorunlar nedeniyle bazen bebekler annelerinin sütünü alamamaktadırlar. Dünya Sağlık Örgütü (DSÖ), bu durumda olan bebekler için süt bankalarından temin edilen sütlerin verilmesini önermekte, bunun mümkün olmadığı durumlarda en son alternatif olarak formül mamalar ile beslenmeyi önermektedir (3). İlk anne sütü bankası 1900'lü yıllarda Boston'da kurulmuş ve Müslüman ülkeler dışında sayıları dünya çapında giderek artmaktadır (4-7). Türkiye'de Sağlık Bakanlığının 2013-2017 stratejik planında anne sütü bankacılığı programı geliştirme ve uygulama hedefi bulunmasına rağmen henüz anne sütü bankası kurulumu gerçekleştirilememiştir (8).
Bu durumun en önemli nedenleri arasında Müslüman ülkelerde süt annelik uygulamasının yaygın olması, anne sütü bankalarından alınan sütlerin dinen yasak evliliklere yol açacağı düşüncesi$\operatorname{dir}(6,7)$. Bununla birlikte ülkemizde anne sütü bankaları ile ilgili yapılan çalışmalarda da sağlık personeli de dahil, kadınların anne sütü bankalarına ilişkin yeterince bilgi sahibi olmadıkları, konuya ilişkin en önemli çekinceler arasında dini nedenlerin ilk sıralarda yer aldığı görülmektedir (9-15). Bu nedenle dünyada sayıları giderek artan anne sütü bankalarının ülkemizde de hizmet verebilmesi için farkındalığın artırılması, toplumun özellikle kadınların konuya ilişkin bilgilendirilmesi önemlidir. Bu çalışma, kadınların anne sütü bankalarına ilişkin bilgi ve görüşlerini belirlemek amacıyla yapılmıştır. Çalışmadan elde edilen sonuçların, toplumumuzun anne sütü bankalarına yönelik yaklaşımlarına ışık tutacağı ve özellikle olumsuz tutumların altında yatan faktörlerin belirlenmesine katkı sağlayacağı düşünülmektedir. 


\section{GEREÇ VE YÖNTEM}

Tanımlayıcı tipteki araştırmanın evrenini Sivas il merkezinde bulunan iki aile sağlığı merkezine kayıtlı 18-49 yaş arası evli kadınlar, örneklemini ise 31.10.2018-31.12.2018 tarihleri arasında çeşitli nedenlerle aile sağlığı merkezlerine başvuran ve araştırmayı kabul eden 190 kadın oluşturmuştur.

\section{Verilerin toplanması}

Veriler araştırmacılar tarafindan Anne Sütü Bankalarına İlişkin Bilgi ve Görüş Formu kullanılarak toplanmıştır. Formun ilk bölümde kadınların yaş, eğitim düzeyi, çalışma durumu, gelir düzeyi, aile tipi, çocuk sayısı, emzirme özellikleri gibi sosyodemografik özelliklere ilişkin 14 soru, ikinci bölümde anne sütü bankalarına ilişkin bilgi ve görüşleri belirlemeye yönelik 17 soru olmak üzere toplam 31 soru bulunmaktadır.

\section{Araştırmanın etik yönü}

Araştırmanın yürütülebilmesi için Sivas Cumhuriyet Üniversitesi Girişimsel Olmayan Klinik Araştırmalar Etik Kurulu'ndan (10.09.2018 tarih ve 2018-09/07sayı) ve araştırmanın yapıldığı kurumlardan izin alınmıştır. Ayrıca annelere araştırmanın ama$\mathrm{Cı}$ açıklanarak Bilgilendirilmiş Onam Formu ile yazılı onamları alınmıştır. Araştırma Helsinki Bildirgesi ilkelerine uygun olarak yürütülmüştür.

\section{Verilerin değerlendirilmesi}

Araştırmadan elde edilen veriler, SPSS for Windows 22.0 paket programı kullanılarak sayı, yüzde, ortalama ölçütleri ve ki-kare testi kullanılarak değerlendirilmiştir. İstatistiksel önemlilik düzeyi $p<0,05$ olarak kabul edilmiştir.

\section{BULGULAR}

Çalışmaya katılan kadınların yaş ortalaması 32,08 $\pm 7,52$ (min:19, maks:49), \%28,9'u ilkokul mezunu, \%57,9'u 0-10 yıldır evli ve $\% 93,2$ 'si çalışmamaktadır. Aile tipinin \%82,6'sında çekirdek aile olduğu, $\% 75,8^{\prime}$ inin il merkezinde yaşadığı, \%81,6'sında gelirin gidere denk olduğu belirlenmiştir.Gebelik, doğum ve yaşayan çocuk sayısı ortalaması sırasıyla 2,56 $\pm 1,55,2,15 \pm 1,36$ ve 2,11 $\pm 1,31$ 'dir. Kadınların \%86,3'ü bebeğini emzirmiş, \%20,1'i ilk alt aydan önce emzirmeyi sonlandırmış ve \%42,7'si ek besinlere başlamıştır. Kadınların \%21,3'ü emzirme sürecinde anne sütü bankasından yararlanmak istediğini ifade etmiştir (Tablo 1).

Tablo 2'de kadınların anne sütü bankaları hakkında bilgi düzeyleri verilmiştir. Kadınların \%75,8'i medya yoluyla olmak üzere $\% 32,6$ 'sı daha önceden anne sütü bankalarını duyduğunu, $\% 90,5$ 'i Türkiye'de anne sütü bankası olup olmadığını bilmediğini, \%67,4'ü Türkiye'de anne sütü bankası olmasını istediğini, \%32,6'sı istemediğini belirtmiştir. Türkiye'de süt bankası olmasını istememe nedenlerinin \%61,3'ünün dini nedenler, \%50'sinin süt bağışı yapan kişiyi tanımamak, \%29'unun toplanan sütlerin karıştırılması ve \%21'inin kayıt sistemine güvensizlik olduğu belirlenmiştir.

Tablo 3'te kadınların anne sütü bankaları hakkındaki görüşlerine ilişkin dağılımı bulunmaktadır. Kadınların \%35,3'ü ihtiyacı olduğunda bebeğini beslemek için süt bankasından süt alabileceğini,
Tablo 1: Kadınların bazı sosyodemografik özelliklerine göre dağılımı

\begin{tabular}{lcc}
\hline Özellikler $(\mathbf{n = 1 9 0 )}$ & $\overline{\mathbf{X}} \pm$ SD (Medyan) & Min-Maks \\
\hline Yaş & $32,08 \pm 7,52(31)$ & $19-49$ \\
Gebelik sayısı & $2,56 \pm 1,55(2)$ & $0-8$ \\
Canlı doğum sayısı & $2,15 \pm 1,36(2)$ & $0-8$ \\
Yaşayan çocuk sayısı & $2,11 \pm 1,31(2)$ & $0-8$ \\
\hline \multicolumn{2}{c}{ Sayı } & $\%$ \\
\hline
\end{tabular}

Eğitim düzeyi ( $n=190)$

$\begin{array}{lcc}\text { Okuryazar değil } & 10 & 5,3 \\ \text { ilkokul } & 55 & 28,9 \\ \text { Ortaokul } & 47 & 24,7 \\ \text { Lise } & 47 & 24,7 \\ \text { Üniversite } & 31 & 16,3\end{array}$

Evlilik yılı $(n=190)$

$\begin{array}{lcc}0-10 \text { yıl } & 110 & 57,9 \\ 11-20 \text { yıl } & 50 & 26,3 \\ 21-30 \text { yıl } & 30 & 15,8\end{array}$

Çalışma durumu $(n=190)$

$\begin{array}{lcc}\text { Çalışıyor } & 13 & 6,8 \\ \text { Çalışmıyor } & 177 & 93,2\end{array}$

Aile tipi ( $n=190)$

Çekirdek aile

Geniş aile

Yaşanılan yer ( $n=190)$

il

75,8

İlçe

Köy

Gelir durumu ( $n=190)$

Gelir giderden az

12,6

Gelir gidere denk

81,6

Gelir giderden fazla

5,8

Emzirme deneyimi ( $n=190)$

Evet

Hayır

ilk altı aydan önce emzirmeyi sonlandırma deneyimi ( $n=164)$

Evet

Hayır

İlk altı aydan önce ek besin başlama deneyimi $(n=164)$

Evet

Hayır

Emzirme sürecinde anne sütü bankasından yararlanmak isteme durumu ( $n=164)$

\begin{tabular}{lcc} 
Evet & 35 & 21,3 \\
Hayır & 129 & 78,7 \\
\hline
\end{tabular}


Tablo 2: Kadınların anne sütü bankaları hakkındaki bilgi düzeyleri

\begin{tabular}{lcc}
\hline Değişkenler & Sayı & $\%$ \\
\hline Anne sütü bankasını duyma ( $\mathbf{n}=\mathbf{1 9 0})$ & 62 & 32,6 \\
$\quad$ Evet & 128 & 67,4 \\
$\quad$ Hayır & & \\
Anne sütü bankasını duyduğu kaynak ( $\mathbf{n}=\mathbf{6 2})$ & & 75,8 \\
$\quad$ Medya (TV, internet) & 9 & 14,5 \\
Aile/Akraba/Komşu & 6 & 9,7 \\
$\quad$ Sağlık Personeli & & \\
Türkiye'de anne sütü bankası var mı? (n=190) & 6 & 3,2 \\
$\quad$ Evet & 6 & 6,3 \\
Hayır & 12 & 90,5 \\
Bilmiyorum & 172 &
\end{tabular}

Türkiye'de anne sütü bankası olmasını isteme $(n=190)$

$\begin{array}{lcc}\text { İsteyen } & 128 & 67,4 \\ \text { İstemeyen } & 62 & 32,6\end{array}$

Türkiye'de anne sütü bankası olmasını istememe nedeni $(n=62) *$

\begin{tabular}{lll} 
Dini nedenler & 38 & 61,3 \\
Süt bağışı yapan kişiyi tanımamak & 31 & 50,0 \\
Toplanan sütlerin karıştııılması & 18 & 29,0 \\
Kayıt sistemine olan güvensizlik & 13 & 21,0 \\
\hline
\end{tabular}

*Birden fazla seçenek işaretlenmiş; yüzdeler $n$ üzerinden alınmıştır.

$\% 46,8^{\prime} i$ ihtiyacı olan kişilerin kullanması için sütünü bankaya bağışlamayı düşünebileceğini, \%55,8'i annelere ihtiyaçları olduğunda süt bankasından anne sütü almalarını önerebileceğini belirtmiştir. Ülkemizde anne sütü bankalarının kurulmasını \%66,3'ü destekleyeceğini, \%48,4'ü anne sütü bankalarına ihtiyaç olduğunu, \%50,5'i anne sütü bankasına talep olacağını, $\% 48,9$ 'sı anne sütü bankalarının toplumumuz için uygun olduğunu düşünmektedir.

Kadınların \%32,1'i süt bankasından süt almanın sosyal yönden problem teşkil edeceğini, $\% 12,1^{\prime} i$ anne sütü bankasına süt bağışlamanın günah olduğunu, \%61,1'i anne sütü bankasından alınan sütlerin bebekler için mamadan daha iyi bir seçenek olduğunu belirtirken, $\% 18,4^{\prime}$ ü bebeklerin sağlığı açısından tehlikeli olduğunu ifade etmiştir.

Kadınların bazı özelliklerine göre anne sütü bankasını duyma durumları incelendiğinde; yaş, eğitim düzeyi, yaşanılan yer ve emzirme deneyimi ile anne sütü bankasını duyma arasında anlamlı fark bulunmuştur $(p<0,05)$ (Tablo 4).

Kadınların bazı özelliklerine göre Türkiye'de anne sütü bankası olmasını isteme durumları arasında anlamlı bir fark bulunmamaktadır ( $p>0,05)$ (Tablo 5).

\section{TARTIŞMA}

Çeşitli nedenlerle bebeğin kendi annesinin sütünü alamadığı durumlarda en uygun seçenek banka sütleridir. Bununla birlikte Türkiye'de anne sütü bankası bulunmamaktadır. Çalışmamızda kadınların \%67,4'ü anne sütü bankalarını duymamış, duyanlar arasında medyanın bilgi kaynağı olarak ilk sırada yer aldığı, sağlık personelinin son sırada olduğu tamamına yakınının $(\% 90,5)$ Türkiye'de anne sütü bankası olup olmadığını bilmediği belirlenmiştir. Benzer şekilde yapılan çalışmalarda Gürel ve Erenel (10) kadınların \%95,1'inin, Gürol ve ark. (12) \%90,6'sının, Can ve Ünülü (14) \%73,2'sinin, Ekşioğlu ve ark. (13) \%58,4'ünün Ergin ve Uzun (16) \%37,5'inin anne sütü bankalarını duymadığını belirlemiştir. Bu durum örneklem grubu özellikleri, yaşanılan bölge ve bilgiye ulaşma kaynaklarının farklıı̆̆ı ile ilişkili olabilir. Çalışmamızda kadınların anne sütü bankasını duyma durumlarını yaş, eğitim düzeyi, yaşadığı yer ve emzirme dene-

Tablo 3: Kadınların anne sütü bankaları hakkındaki görüşleri $(n=190)$

\begin{tabular}{|c|c|c|c|}
\hline İfadeler & $\begin{array}{c}\text { Katılıyorum } \\
\text { Sayı (\%) }\end{array}$ & $\begin{array}{c}\text { Kararsızım } \\
\text { Sayı (\%) }\end{array}$ & $\begin{array}{c}\text { Katılmıyorum } \\
\text { Sayı (\%) }\end{array}$ \\
\hline İhtiyacım olduğunda bebeğimi beslemek için süt bankasından süt alırım. & $67(35,3)$ & $51(26,8)$ & $72(37,9)$ \\
\hline İhtiyacı olan kişilerin kullanması için sütümü süt bankasına bağışlamayı düşünürüm. & $89(46,8)$ & $49(25,8)$ & $52(27,4)$ \\
\hline Annelere ihtiyaçları olduğunda süt bankasından anne sütü almalarını öneririm. & $106(55,8)$ & $44(23,2)$ & $40(21,1)$ \\
\hline Türkiye'de anne sütü bankalarının kurulmasını desteklerim. & $126(66,3)$ & $30(15,8)$ & $34(17,9)$ \\
\hline Süt bankasından süt almak sosyal yönden problem teşkil eder. & $61(32,1)$ & $58(30,5)$ & $71(37,4)$ \\
\hline Bebeğin süt bankasından alınan anne sütü ile beslenmesi günahtır. & $38(20,0)$ & $44(23,2)$ & $108(56,8)$ \\
\hline Anne sütü bankasına süt bağışlamak günahtır. & $23(12,1)$ & $50(26,3)$ & $117(61,6)$ \\
\hline Ülkemizde anne sütü bankasına talep olur. & $96(50,5)$ & $65(34,2)$ & $29(15,3)$ \\
\hline Anne sütü bankasından alınan sütler bebekler için mamadan daha iyi bir seçenektir. & $116(61,1)$ & $34(17,9)$ & $40(21,1)$ \\
\hline Anne sütü bankasından alınan sütlerle bebeklerin beslenmesi sağlık açısından tehlikelidir. & $35(18,4)$ & $58(30,5)$ & $97(51,1)$ \\
\hline Ülkemizde anne sütü bankalarına ihtiyaç vardır. & $92(48,4)$ & $60(31,6)$ & $38(20,0)$ \\
\hline
\end{tabular}


Tablo 4: Kadınların bazı özelliklerine göre anne sütü bankasını duyma durumlarının dağılımı

\begin{tabular}{|c|c|c|c|}
\hline \multirow[b]{2}{*}{ Özellikler } & \multicolumn{2}{|c|}{ Anne sütü bankasını } & \multirow[b]{2}{*}{$X^{2} / p$} \\
\hline & $\begin{array}{c}\text { Duyan } \\
\text { Sayı (\%) }\end{array}$ & $\begin{array}{c}\text { Duymayan } \\
\text { Sayı (\%) }\end{array}$ & \\
\hline \multicolumn{4}{|l|}{ Yaş grubu } \\
\hline 30 yaş ve altı & $19(20,7)$ & $73(79,3)$ & $11,644 / 0,001$ \\
\hline 31 yaş ve üzeri & $43(43,9)$ & $55(56,1)$ & \\
\hline \multicolumn{4}{|l|}{ Eğitim durumu } \\
\hline Ortaokul ve daha az & $29(25,9)$ & $83(74,1)$ & $5,636 / 0,018$ \\
\hline Lise ve Üniversite & $33(42,3)$ & $45(57,7)$ & \\
\hline \multicolumn{4}{|l|}{ Yaşanılan yer } \\
\hline İl merkezi & $53(36,8)$ & $91(63,2)$ & $4,714 / 0,030$ \\
\hline Köy / Kasaba / İlçe & $9(19,6)$ & $37(80,4)$ & \\
\hline \multicolumn{4}{|l|}{ Gelir durumu } \\
\hline Geliri giderden az & $7(29,2)$ & $17(70,8)$ & $0,150 / 0,699$ \\
\hline Geliri gidere denk ya da fazla & $55(33,1)$ & $111(66,9)$ & \\
\hline \multicolumn{4}{|l|}{ Çalışma durumu } \\
\hline Çalışıyor & $6(46,2)$ & $7(53,8)$ & $1,161 / 0,281$ \\
\hline Çalışmıyor & $56(31,6)$ & $121(68,4)$ & \\
\hline \multicolumn{4}{|l|}{ Aile tipi } \\
\hline Çekirdek & $53(33,8)$ & $104(66,2)$ & $0,522 / 0,470$ \\
\hline Geniş & $9(27,3)$ & $24(72,7)$ & \\
\hline \multicolumn{4}{|l|}{ Emzirme deneyimi olma } \\
\hline Olan & $59(36,0)$ & $105(64,0)$ & $6,096 / 0,014$ \\
\hline Olmayan & $3(11,5)$ & $23(88,5)$ & \\
\hline \multicolumn{4}{|c|}{ ilk altı aydan önce emzirmeyi sonlandırma deneyimi } \\
\hline Olan & $12(36,4)$ & $21(63,6)$ & $0,003 / 0,959$ \\
\hline Olmayan & $47(35,9)$ & $84(64,1)$ & \\
\hline \multicolumn{4}{|c|}{ İlk altı aydan önce bebeğine ek besin } \\
\hline Veren & $25(35,7)$ & $45(64,3)$ & $0,004 / 0,952$ \\
\hline Vermeyen & $34(36,2)$ & $60(63,8)$ & \\
\hline
\end{tabular}

yimlerinin etkilediği belirlenmiştir. Yenidoğan yoğun bakım ünitesinde bebeği yatan annelerle yapılan bir çalışmada annelerin süt bankalarından yararlanma ve süt bağışlama isteğini eğitim durumu, uzun süre yaşadıkları yer ve emzirme deneyimlerinin etkiledikleri belirlenmiştir (10). Başka bir çalışmada kadınların yaşının süt anne olma durumunu, eğitim düzeylerinin ise süt bağışlama ve paylaşma isteklerini etkilediği bulunmuştur (16).

Çalışmamızda kadınların anne sütü bankaları hakkında görüşleri incelendiğinde çoğunluğunun olumlu yönde görüş bildirdiği görülmektedir. Kadınların yarıdan fazlası ülkemizde anne sütü bankalarının kurulmasını istediğini ve desteklediğini belirtmiştir. Benzer şekilde yapılan diğer çalışmalarda da katılımcıların anne sütü bankalarının kurulmasını destekledikleri belirlenmiştir (10-13). Kadınların yarısı anne sütü bankalarına talep olacağını ve anne sütü bankalarının toplumumuz için uygun olduğunu düşünmektedir. Kadınların yaklaşık üçte biri $(\% 35,3)$ intiyacı olduğunda bebeğini beslemek için süt bankasından süt alabileceğini, yarıdan fazlası annelere ihtiyaçları olduğunda süt bankasını önerebileceğini belirtmiştir. Pekyiğit ve ark. (17) tarafindan yapılan çalışmada da benzer sonuçlar elde edilmiştir. ÇaIışmamızda kadınların \%46,8'i ihtiyacı olan kişilerin kullanması için sütünü bankaya bağışlamayı düşünebileceğini belirtmiştir. Benzer şekilde yapılan çalışmalarda sütünü bağışlamayı düşünen kadınların oranı \%43,4 ile \%68,8 arasında değişmektedir $(13,17,18)$. Doğu Etiyopya'da yapılan bir çalışmada katılımcıların \%11'i sütünü bankaya bağışlamak istediğini belirtmiştir (19). Anne sütü bağışçıları ile yapılan nitel bir çalışmada annelerin başkalarını düşünme, hasta ve prematüre bebeklere yardım etme isteği ve sütünü boşa harcamak istememesi gibi nedenlerle sütlerini bağışladıkları belirlenmiştir (20). 
Tablo 5: Kadınların bazı özelliklerine göre Türkiye'de anne sütü bankası olmasını isteme durumunun dağılımı

\begin{tabular}{|c|c|c|c|}
\hline \multirow[b]{2}{*}{ Özellikler } & \multicolumn{2}{|c|}{ Türkiye’de anne sütü bankası olmasını } & \multirow[b]{2}{*}{$x^{2} / p$} \\
\hline & $\begin{array}{l}\text { İsteyen } \\
\text { Sayı (\%) }\end{array}$ & $\begin{array}{c}\text { İstemeyen } \\
\text { Sayı (\%) }\end{array}$ & \\
\hline \multicolumn{4}{|l|}{ Yaş } \\
\hline 30 yaş ve altı & $66(71,7)$ & $26(28,3)$ & $1,550 / 0,213$ \\
\hline 31 yaş ve üzeri & $62(63,3)$ & $36(36,7)$ & \\
\hline \multicolumn{4}{|l|}{ Eğitim durumu } \\
\hline Ortaokul ve daha az & $77(68,8)$ & $35(31,3)$ & $0,237 / 0,626$ \\
\hline Lise ve Üniversite & $51(65,4)$ & $27(34,6)$ & \\
\hline \multicolumn{4}{|l|}{ Yaşanılan yer } \\
\hline îl merkezi & $96(66,7)$ & $48(33,3)$ & $0,133 / 0,715$ \\
\hline Köy / Kasaba / İlçe & $32(69,6)$ & $14(30,4)$ & \\
\hline \multicolumn{4}{|l|}{ Gelir durumu } \\
\hline Geliri giderden az & $15(62,5)$ & $9(37,5)$ & $0,296 / 0,586$ \\
\hline Geliri gidere denk ya da fazla & $113(68,1)$ & $53(31,9)$ & \\
\hline \multicolumn{4}{|l|}{ Çalışma durumu } \\
\hline Çalışıyor & $10(76,9)$ & $3(23,1)$ & $0,580 / 0,447$ \\
\hline Çalışmıyor & $118(66,7)$ & $59(33,3)$ & \\
\hline \multicolumn{4}{|l|}{ Aile tipi } \\
\hline Çekirdek & $106(67,5)$ & $51(32,5)$ & $0,009 / 0,925$ \\
\hline Geniş & $22(66,7)$ & $11(33,3)$ & \\
\hline \multicolumn{4}{|l|}{ Anne sütü bankasını duyma } \\
\hline Duyan & $38(61,3)$ & $24(38,7)$ & $1,163 / 0,281$ \\
\hline Duymayan & $90(70,3)$ & $38(29,7)$ & \\
\hline \multicolumn{4}{|l|}{ Emzirme deneyimi olma } \\
\hline Olan & $108(65,9)$ & $56(34,1)$ & $1,251 / 0,263$ \\
\hline Olmayan & $20(76,9)$ & $6(23,1)$ & \\
\hline \multicolumn{4}{|c|}{ İlk altı aydan önce emzirmeyi sonlandırma deneyimi } \\
\hline Olan & $18(54,5)$ & $15(45,5)$ & $2,349 / 0,125$ \\
\hline Olmayan & $90(68,7)$ & $41(31,3)$ & \\
\hline \multicolumn{4}{|c|}{ İlk altı aydan önce ek besin başlama deneyimi } \\
\hline Olan & $43(61,4)$ & $27(28,6)$ & $1,063 / 0,302$ \\
\hline Olmayan & $65(69,1)$ & $29(30,9)$ & \\
\hline
\end{tabular}

İslam dininde anne sütü bebekler için en uygun besin kaynağı olarak kabul edilir. Ancak aynı annenin sütünü paylaşan çocukların sütkardeş olduklarına ve bu nedenle birbirleriyle evlenemeyeceklerine inanılmaktadır (5-7). Çalışmamızda bebeğini süt bankasından alınan sütle besleme veya süt bankasına süt bağışlamanın günah olduğuna katılmayanların oranının yarıdan fazla olduğu görülmektedir. Bu sonuç kadınların dini endişeler taşımakla birlikte anne sütü bankaları konusunda genel anlamda olumlu oldukları şeklinde yorumlanabilir. Ülkemizde yapılan benzer çalışmalarda da kadınların anne sütü bankalarına dini, sosyal ve ahlaki nedenlerle olumsuz yaklaşttkları belirlenmiştir $(10,12,13,18)$. Anneler dini açıdan sütkardeşlerin evlenmeleri- nin yasak olduğunu düşünerek anne sütü bankalarının ilerde sorunlara yol açabileceğini belirtmiştir $(16,21)$. Buna yönelik olarak ülkemiz için anne sütü merkezlerinin kurulmasına ilişkin sistem tedbirleri kapsamında birden fazla anneye ait sütlerin karıştırılmaması, sütlerin aynı cinsiyetteki bebeklere verilmesi, iyi bir barkod ve otomasyonu içeren güvenli kayıt sisteminin oluşturulması önerilmektedir (22).

Çalışmamızda kadınların yaklaşık beşte biri $(\% 18,4)$ süt bankasından süt almanın bebeklerin sağlığı açısından tehlikeli olduğunu ifade etmiştir. Yurtdışında yapılan çalışmalarda anneler süt bankasından süt almanın enfeksiyon ve hastalık bulaşma riskine yol açabileceğini belirtmiştir $(19,23,24)$. Ülkemizde ya- 
pılan çalışmalarda da kadınların hastalık bulaşma riski ve bağışlanan sütlerin temiz olmamasına yönelik endişeler taşıdığı belirlenmiştir $(11,13,15,18)$. Bu nedenle anne sütü bankalarında gerekli denetim ve hijyenik koşulların sağlanması ve annelerin buna ilişkin kaygılarının giderilmesi önemlidir. Çalışmamızda \%61,1'i anne sütü bankasından alınan sütlerin bebekler için mamadan daha iyi bir seçenek olduğunu belirtmiştir. Preterm ve düşük doğum ağırlıklı bebeklerde formül mama ile donör anne sütü karşılaştırıldığında mama ile beslenenlerde nekrotizanenterokolit gelişme riskinin arttı̆ı bildirilmektedir (25). Yapılan bir çalışmada yenidoğan biriminde anne sütü bankası açılmasının, bebeklerde ilk dört hafta mama ile beslenmeyi azalttı̆ı ve enteral beslenmenin daha erken başlamasını sağladığı belirlenmiştir (26).

\section{Sınırlılıklar}

Bu çalışmanın tek merkezde gerçekleştirilmiş olması bir sınırlılık olarak ele alınabilir. Bu nedenle çalışma sonuçları sadece örneklem grubuna genellenebilir. Konuya ilişkin daha kapsamlı bilgi elde etmek için, farklı sosyokültürel özellikteki geniş örneklemlerde ileri çalışmalar planlanabilir.

\section{SONUÇ}

Kadınların anne sütü bankaları hakkında yeterince bilgi sahibi olmadığı, anne sütü bankalarının kurulmasını istediği ancak dini, sosyal, sağlık açısından etkileri konusunda kaygılarının olduğu görülmektedir. Süt bankalarının kurulabilmesi için atılacak en önemli adımlardan birisi toplumun anne sütü bankalarını istememe nedenlerinin dikkate alınması ve kaygılarının giderilmesi için diyanet kurumu yetkilileri ile işbirliği yapılması ve konuya ilişkin toplumun bilgilendirilmesine yönelik faaliyetlerde bulunulmalıdır.

Etik Komite Onayı: Bu çalışma Sivas Cumhuriyet Üniversitesi Girişimsel Olmayan Klinik Araştırmalar Etik Kurulu'ndan 10.09.2018 tarihli ve 2018-09/07 sayılı karar ile onay almıştr.

Bilgilendirilmiş Onam: Katılımcılardan bilgilendirilmiş onam alınmıştır.

Hakem Değerlendirmesi: Dış bağımsız.

Yazar Katkıları: Çalışma Konsepti/Tasarım- Z.G., A.Ş.E.; Veri Toplamai.Y.; Veri Analizi/Yorumlama- I.Y., Z.G.; Yazı Taslağı- I.Y.; İçeriğin Eleştirel İncelemesi- Z.G., A.Ş.E.; Son Onay ve Sorumluluk- I.Y., Z.G., A.Ş.E.; Malzeme ve Teknik Destek- I.Y.; Süpervizyon- Z.G., A.Ş.E.

Çıkar Çatışması: Yazarlar çıkar çatışması beyan etmemişlerdir.

Finansal Destek: Yazarlar finansal destek beyan etmemişlerdir.

Ethics Committee Approval: This study was approved by the Sivas Cumhuriyet University Non-Invasive Clinical Research Ethics Committee on 10.09.2018 with the decision numbered 2018-09/07.

Informed Consent: Written consent was obtained from the participants.

Peer Review: Externally peer-reviewed.
Author Contributions: Conception/Design of Study- Z.G., A.Ş.E.; Data Acquisition- i.Y.; Data Analysis/Interpretation- I.Y., Z.G.; Drafting Manuscript- I.Y.; Critical Revision of Manuscript- Z.G., A.Ş.E.; Final Approval and Accountability- I.Y., Z.G., A.Ş.E.; Material and Technical Support- I.Y.; Supervision- Z.G., A.Ş.E.

Conflict of Interest: Authors declared no conflict of interest.

Financial Disclosure: Authors declared no financial support.

\section{KAYNAKLAR/REFERENCES}

1. Gartner LM, Morton J, Lawrence RA, Naylor AJ, O'Hare D, Schanler RJ, et.al. American Academy of PediatricsSection on Breastfeeding. Breastfeeding and the use of human milk. Pediatrics 2005;115(2):496-506

2. Yılmaz Bal H, Bolışık B. Çocuklarda Beslenme. Conk Z, Başbakkal Z, Yılmaz Bal H, Bolışık B (Ed), Pediatri Hemşireliği. 1. Baskı, Güneş Tıp Kitabevleri, İstanbul, 2013:543-58.

3. Global Strategy for Infant andYoung Child Feeding https://apps. who.int/iris/bitstream/handle/10665/42590/9241562218. pdf?sequence=1 Erişim Tarihi 07.11.2020

4. Human Milk Banking Association of North America. Erişim: https:// www.hmbana.org/ Erişim Tarihi:07.11.2020

5. Ghaly M. Human milk-based industry in the Muslim World: Religio ethical challenges. Breastfeed Med 2018;13(S1):28-9.

6. Alnakshabandi K, Fiester A. Creating religiously compliant milk banks in the Muslim world: a commentary. Paediatr Int Child Health 2016;36(1):4-6.

7. Pekdemir Ş. (2015) İslam Hukukuna Göre Anne Sütü Bankaları. The Journal of Academic Social Science Studies 40:537-54.

8. Sağlık Bakanlığı Stratejik Plan, 2013-2017https://titck.gov.tr/ Dosyalar/TibbiCihaz/ProjeveStrateji/Sa\%C4\%9FI\%C4\%B1k\%20 Bakanl\%C4\%B1\%C4\%9F\%C4\%B1\%20Stratejik\%20Plan.pdf Erişim Tarihi: 07.11.2020

9. Şentürk Erenel A, Ünal Toprak F, Gölbaşı Z, Pelit Aksu S, Arslan Gürcüoğlu Esra, Uçar T, et.al. Sağlık personelinin anne sütü bankalarına ilişkin bilgi ve görüşlerinin belirlenmesine yönelik çok merkezli bir çalışma. Gazi Medical Journal 2017;28:107-11.

10. Gürel R, Erenel Şentürk $A$. Knowledge and view of mothers whose babies in newborn intensive care units about breast milk banking in Turkey. Cyprus J MedSci 2020;5(1):51-6.

11. Özaydın T, Alan Dikmen H, Dereli Yılmaz S, Karakoç Geçici A. 0-6 aylık bebeği olan annelerin anne sütü bankacılığı hakkındaki bilgi durumunun ve görüşlerinin değerlendirilmesi. STED 2019;28(3):153-62.

12. Gürol A, Özkan H, Çelebioğlu A. Turkish women's knowledge and views regarding mothers milk banking. Collegian 2014;21(3):239-44.

13. Ekşioğlu A, Yeşil Y, Turfan E. Mothers' views of milk banking: sample of İzmir. Turk Pediatri Ars 2015;50(2):83-9.

14. Can Ş, Ünülü M. Knowledge of mother regarding wet nursery and breas tmilk banking. Ankara Med J 2019;19(1):60-70.

15. Yılmaz M, Aykut $M$, Şahin $H$, Ongan D, Balcı E, Gün $i$, et al. Knowledge, attitude, and practices about wet-nursing and human milk banking in Kayseri, Turkey. Erciyes Med J 2018;40 (4):204-9.

16. Ergin A, Uzun SU. Turkish women's knowledge, attitudes, and behaviors on wet-nursing, milk sharing and human milk banking. Matern Child Health J 2018;22(4):454-60. 
17. Pekyiğit A, Yıldız D, Eren Fidancı B, Çalık B, Dehmen Ö, Koçak T, et.al. Annelerin donör süt ve süt bankalarına ilişkin görüşleri. Güncel Pediatri 2019;17(3):336-325.

18. Kaya Senol D, Aslan E. Women's opinions about human milk donation and human milk banking. Biomedical Research 2017;28(15):6866-71.

19. Gelano TF, Bacha YD, Assefa N, Motumma A, Roba AA, Ayele Y, et.al. Acceptability of donor breastmilk banking, its use for feding infants, and associated factors among mothers in eastern Ethiopia. IntBreastfeed J 2018;13:23.

20. Wambach K, Bateson T, Matheny P, Easter-Brown K. A descriptive study of the attitudes, perceptions, and experiences of human milk donation. Adv Neonatal Care 2019;19(6):441-51.

21. Karadağ A, Özdemir R, Ak M, Özer A, Dogan GD, Elkiran Ö. Human milk banking and milk kinship: Perspectives of mothers in a Muslim country. J Trop Pediatr 2015;61(3):188-96.
22. Kabasakal E, Bozkurt Ö. Türkiye'de anne sütü merkezi girişimlerinin değerlendirilmesi ve sistem önerisi. J Contemp Med 2019;9(4):41723.

23. Leung JCY, Yau SY. Perceptions of breastfeeding mothers on breastmilk donation and establishment of human breastmilk bank in Hong Kong: A qualitative study. International Journal of Nursing 2015;2(2):72-80.

24. Abhulimhen-Iyoha BI, Okonkwo IR, Ideh RC, Okolo AA. Mothers' perception of the use of banked human milk for feeding of the infants. Niger J Paed 2015;42(3):223-7.

25. Quigley M, Embleton ND, McGuire W. Formula versus donor breast milk for feding preterm or low birth weight infants. Cochrane Database of SystematicReviews 2019, Issue 7. Art. No.: CD002971.

26. Utrera Torres MI, Medina López C, Vázquez RománS, AlonsoDíaz C, Cruz-Rojo J, Fernández Cooke E. Does opening a milk bank in a neonatal unit change infant feding practices? A before and after study. Int Breastfeed J 2010;5:4. 